\title{
Successful CO2 Laser Treatment of Facial Angiofibromas in a Female Patient with Tuberous Sclerosis: Case Report
}

\author{
Julian Penev ${ }^{1}$, Ilko Bakardzhiev ${ }^{1 *}$, Margarita Gospodinova ${ }^{1}$ \\ ${ }^{1}$ Department of Infections Diseases and Dermatology, Medical University of Varna, Bulgaria \\ ${ }^{*}$ Medical College, Medical Univerity of Varna, Bulgaria
}

Received: January 15, 2019; Accepted: February 12, 2019 ; Published: February 15, 2019

*Corresponding author: Ilko Bakardzhiev, Associate Professor, Medical College, Medical University of Varna, Tsar Osvoboditel 84, Bulgaria, Tel:+359888 768413; E-mail: varna2008@gmail.com

\begin{abstract}
Tuberous sclerosis (Morbus Bourneville-Pringle) is a rare, multisystemic,autosomal dominant disease, associated with a mutation of either of two genes TSC1 and TSC2, responsible for synthesis of proteins hamartin and tuberin - tumor growth suppressing factors, involved in cell proliferation and differentiation processes. Perhaps the most common findings of TS are angiophibromas cutaneous manifestations of the disease, serving as clinical pointers to the diagnosis. Different methods are being used to treat facial angiofibromas with little or no success. Treatment with $\mathrm{CO} 2$ laser ablation can provide fruitful results in removing facial angiofibromas.

Presented is a case of a 40 year-old female patient, diagnosed with tuberous sclerosis with multiple facial angiofibromas, subjected to $\mathrm{CO} 2$ laser ablation.
\end{abstract}

Keywords: Angiofibroma; tuberous sclerosis; TSC; BournevillePringle; CO2 laser ablation;

\section{Abbreviations}

(AF) - Angiofibroma

(TSC) - Tuberous Sclerosis Complex

(CO2) - Carbon Dioxide

(TSC1) - Gene coding hamartin

(TSC2) - Gene coding tuberin

\section{Introduction}

Tuberous sclerosis, also called Tuberous sclerosis complex (TSC) can affect virtually all vital organs, causing benign tumors to grow in them. Those benign tumors extend to the areas of head, heart, brain, and kidneys [4]. Tuberous sclerosis is easily seen and diagnosed in early childhood with the manifestation of angiofibroma on the face. Facial angiofibromas are a social problem for those suffering of tuberous sclerosis, additionally worsening their already impaired social life, interpersonal interaction, and daily activities.

\section{Case report}

A 40 year-old female patient diagnosed with tuberous sclerosis (Morbus Bourneville-Pringle). Patient reported initial angiofibroma eruption around nasal region appeared at 5 years of age. Lesions were then scarce, and dischydradenoma eruptivum, Erythema teleangiectaticum, verruce plane juvenilis and Morbus Bourneville-Pringle were discussed as possible differential diagnosis. Neurological symptoms appear for the very first time when patient was at 10 years of age with the presence of epileptic seizures, as these neurological symptoms confirm diagnosis of tuberous sclerosis. At 20 years of age longitudinal nail plate depressions, as well as Koenen (garlic-clove) tumors appeared (Figure-1). Patient is currently on anti-epileptic drug therapy.

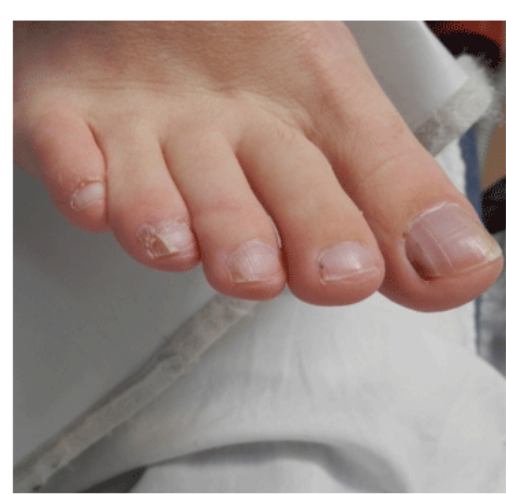

Figure 1: Longitudinal nail plate depressions, and Koenen (garlic-clove) tumors present

The patient presented slight neurological impairment. She was able to communicate her thoughts and complains. She articulated her desire to eliminate the cutaneous manifestations of the disease on her face, mainly under aesthetic considerations, as for the past 35 years lesions got bigger and larger, worsening her quality of life (Figure-2). 


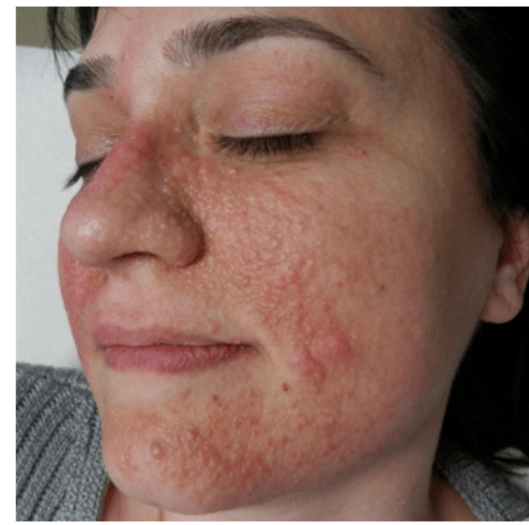

Figure 2: Clinical manifestations

Series of therapy sessions of lesion ablation with a CO2 laser were performed, as initially conducted on the right side of the face in order to determine therapy efficiency. Two months past starting therapy, the left side of her face was also treated. Laser ablation treatment was conducted under $5 \mathrm{X}$ optical magnification in order to remove even the tiniest lesions, and performed under topical anesthesia (Emla). During therapy sessions no epileptic seizures were elicited, which was the main expected complication. An excellent therapeutic and aesthetic result even after the first laser session was observed, which motivated patient in continuing treatment.

Lesions were ablated slightly below the level of surrounding tissue. Superpuls mode with an average optical power of $4 \mathrm{~W}$ with small focal spots up to $2 \mathrm{~mm}$ was applied (Figure-3). Topical powdered antibiotic was prescribed post treatment in order to help under crust epithelialization, and for achieving a better aesthetic result. Laser treatment sessions were conducted every other month, as residual lesions were removed on a step by step basis. Lesions larger than $7 \mathrm{~mm}$ of diameter were also treated on stages, reducing this way their size gradually. An untreated area around each lesion was left, using a checkerboard pattern. Within one year the skin became visibly smoother, as erythema the points of impact continued to fade gradually. Borders of the nose

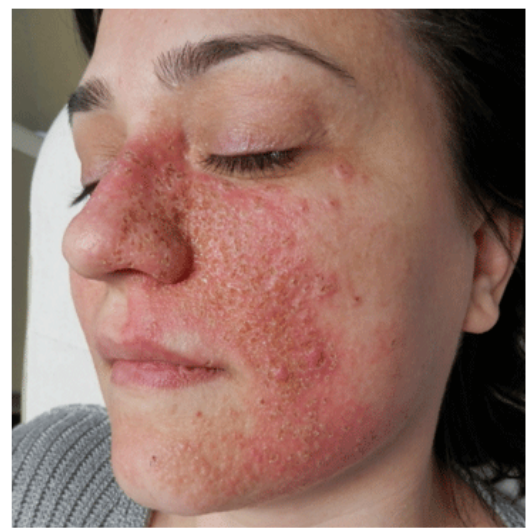

Figure 3: CTypical view of the treated area immediately after $\mathrm{CO} 2$ laser ablation were subjected to a laser ablation in-depth, since lesions merged together and deformed nose shape. As a result of this ablation, nasal folds become more notabe and sculptured (Figure-4). Patient reported highly improved self-esteem post laser therapy.

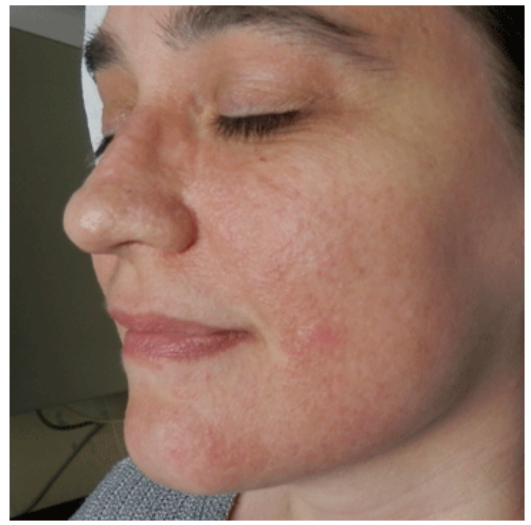

Figure 4: Clinical results at late stage of treatment

\section{Discussion}

Removing facial angiofibromas in TS with CO2 laser ablation is an outpatient, minimally invasive, bloodless and seamless laser procedure. $\mathrm{CO} 2$ laser is the most preferable mean of laser treatment due to the following reasons: Nd:Yag laser is known to leave boxcar scars, and rolling scars, and keloids in some cases. Use of pulsed dye laser is not to be considered either, since the vascular component is not major in TSC angiofibromas, and the right fluence for treating lesions of various sizes cannot be precisely determined. Last but not least, the use of lasers in the visible and near infrared range can accidentally damage eyesight, as tears of the human eye completely absorb scattered radiation of the CO2 laser. This opinion is supported by other authors [3-6].

Angiofibromas tend to grow slow. Once removed, aadditional CO2 laser therapy should be applied during the follow-ups to correct newly appeared tumor vegetations. Research provides evidence that rapamycin therapy is a new treatment option [5, 7-8]. Rapamycin therapy could stop the process of emergence of new lesions, and growth of the already existing ones. Removal of existing lesions using an ablative $\mathrm{CO} 2$ laser, and subsequent treatment with rapamycin could be a good solution for the treatment of cutaneous manifestation of this genetic disease [8].

\section{Conclusion}

Stepwise checkerboard-like laser ablation of facial angiofibromas ensures an aesthetic outcome with no noticeable facial scarring. CO2 laser ablation is to be considered as an effective choice of treatment in eliminating skin manifestations of TSC $[1,2,8,9]$. Effective laser treatment delivers an aesthetic result, which may improve self-esteem and quality of life of these patients. Of course, they should be monitored for brain, eye, renal, pulmonary and cardiac accompanying symptoms, as TSC is a genetic disorder with a slow, yet progressive behavior. 


\section{References}

1. Biondo G, Greco S, Mavilia L, Mercuri SR. Treatment of nodular facial angiofibromas in tuberous sclerosis, using ultrapulse carbon dioxide laser. Clinical and Experimental Dermatology. CED. 2014;39(6):738740.

2. Bellack GS, Shapshay SM. Management of Facial Angiofibromas in Tuberous Sclerosis: Use of the Carbon Dioxide Laser. OtolaryngologyHead and Neck Surgery.1986. doi:10.1177/019459988609400106

3. Boixeda P, Sánchez-Miralles E, Azaña JM, Arrazola JM, Moreno R, Ledo A. CO2, argon, and pulsed dye laser treatment of angiofibromas. J Dermatol Surg. Oncol. 1994;20(12):808-812.

4. Cutando A, Gil JA, López J. Oral health management implications in patients with tuberous sclerosis. Oral Surg Oral Med Oral Pathol Oral Radiol Endod. 2000;89:430-435. doi: 10.1067/moe.2000.105766

5. Madke B. Topical rapamycin (sirolimus) for facial angiofibromas. Indian Dermatol Online J. 2013;4(1):54-57. doi: 10.4103/22295178.105488
6. Michel JL, Grognard C, Toubel G, Cartier H, Fusade T, Perrin D. CO2, Er:YAG and Pulsed Dye Laser Treatment of Angiofibromas in Patients with Tuberous Sclerosis. Medical Laser Application. 2004;19(3):136145 doi: 10.1078/1615-1615-00135

7. Moavero R, Coniglio A, Garaci F, Curatolo P. Is mTOR inhibition a systemic treatment for tuberous sclerosis? Italian Journal of Pediatrics Sept. 2013:39:57. doi.org/10.1186/1824-7288-39-57

8. Park J, Yun SK, Cho YS, Song KH, Kim HU. Treatment of Angiofibromas in Tuberous Sclerosis Complex: The Effect of Topical Rapamycin and Concomitant Laser Therapy. Dermatology. 2014;228:37-41 doi:10.1159/000357033

9. Song MG, Park KB, Lee ES. Resurfacing of Facial Angiofibromas in Tuberous Sclerosis Patients Using CO 2 Laser with Flashscanner. Dermatologic Surgery. 1999;25(12):970-973. 